effective than single-agent therapy; well, it all depends what you mean by "more effective." It is true that the aggressive combined regimens applied in advanced breast cancer produce more immediate objective responses; but, as has recently been pointed out, this has not been reflected in any overall improvement in survival. ${ }^{7}$ Furthermore, a recent paper has shown that a sequence of single agents used in advanced breast cancer will eventually produce the same result as combining all agents together at the first injection. ${ }^{8}$ Next, a consensus of opinion broadcast from the National Institutes of Health by a group of distinguished and committed medical oncologists, does not make me tremble at the knees as if a pronouncement has come down from Mount Olympus. Medical oncologists in America are notorious for their tunnel vision and have to continue struggling to justify their very existence as a specialty. Furthermore, as already pointed out, practice in the United States can never be transplanted to the United Kingdom or the developing world without an enormous investment in capital and recurren expenditure.

Finally, let us remember that only $8 \%$ of patients with breast cancer are being entered into prospective trials in the United Kingdom each year. ${ }^{9}$ This may be due to inertia on the part of clinicians, but it is more likely that the prospective trials so far offered to busy clinicians are very demanding in unrewarded effort and often unrealistic in their proposals. There are plenty of patients available to answer all the questions applying to the management of early breast cancer; there is certainly room for groups investigating $\mathrm{Dr}$ Price's approach as well as for groups of clinicians who are interested in the modest benefits that might accrue as a result of applying the soft option.

\section{Michael Baum}

\section{Department of Surgery, \\ Medical School, \\ London SE5 8RX} ${ }^{1}$ Hill T, Price LA. In: Stoll BA, ed. Secondary spread
in breast cancer. London: Heinemann, 1977:193-211.
${ }^{2}$ Maguire GP, Tait A, Brooke M, Thomas C, Howat
JMT, Sellwood RA, Bush H. Br Med $\mathcal{1}$ 1980;281: JMT, Sellwood RA, Bush H. Br Med f 1980;281 : $1179-80$.

${ }^{3}$ Meakin JW, Alt WEC, Beale FA, et al. In: Adjuvant therapy of cancer. Salmon SE, Jones SE, eds. Amsterdam: Elsevier/North Holland Biomedical
Press, 1977.

Nissen Meyer R, Kjellgren K, Malmio K, Mansson B, Norin T. Cancer 1978;41:2088-98.

1970;172:711-32.

Donovan IA, Morrisey DM, Powell J, Waterhouse JAH. Lancet 1976;i:42.

Powles TJ, Coombes RC, Smith IE, Jones JM, Ford HT, Gazet JC. Lancet 1980;i:580-2

8 Paterson AHG, Lees AW, Hanson J, Szafran O,

Cornish F. Lancet 1980; : 312 .

1979;ii:623-5.

\section{Statistics and ethics in medical research}

SIR,-I was disappointed to read Mr Douglas Altman's article (8 November, p 1267), suggesting that the use of placebos in trials was excessive. More detail should have been provided. Certainly the absence of a placebo group in trials of psychotropic drugs has led to the prescribing of numerous compounds of highly doubtful value.

A particular example is the proliferation of so-called antidepressants, where in a "piggyback" fashion newer antidepressants have been compared with older forms so that these in turn become regarded as established treatments and provide the reference for yet newer drugs. Unfortunately, even the most established antidepressant drugs have been shown in many trials to be little or not at all superior to placebo, and the nature of the sample of patients and the design of the trial have obviously been critical. This means that later comparisons of newer drugs with these, without a placebo group, have been almost meaningless

A further serious problem has been the total neglect of the role of type II error and the $\beta$ probability associated with this. This is the probability that when trying to sustain the nul hypothesis, which is that two drugs are equally potent, this could have arisen purely by chance. Unlike the $\alpha$ probability for type I error, which is required when attempting to reject the null hypothesis, as is the case in placebo comparisons, the $\beta$ probability is usually very substantial unless one has quite large numbers, five or 10 times the number used in placebo trials. The glib statement that, for instance, 15 patients on an established drug and 15 patients on a new drug showed no difference significant at the $5 \%$ level (where this is always given as the $\alpha$ probability) has led to the use of what are in fact virtually untried compounds.

Of course it is of practical significance to compare truly established methods of treatment with newer therapy, but this is only realistic and of value where the methodologica considerations for that comparison are such that they do not lead to this common form of mathematical nonsense.

It is to be hoped that, in psychiatry at least, the placebo will be encouraged rather than the reverse in future research.

GERALd SilvermaN

Ealing Hospital,
Southall, Middx UB1 3EU

\section{What is a nuclear shelter?}

SIR,-Since there are no licensing or approval procedures in this country, and most others, the entrepreneurs have entered this field; it seems that just about anybody can market a "nuclear shelter." As an independent, objective, and knowledgeable nuclear physician who really does understand what the effects of a nuclear explosion are, I am alarmed to find a lamentable lack of information in the "nuclear shelter" brochures about the radiation protection factors.

Outside the zone of the physical effects of a nuclear explosion the problem is one of protection from the immediate gamma rays and the substantial aerial and deposited radioactive debris and dust. As ground zero is approached these radiation hazards increase about logarithmically. Quite near the bomb the radiation hazards mount steeply with the superimposition of more instantaneous gamma rays on neutron-induced radioactivity in the air and earth and more continuing gamma rays from relatively more terrestrial fallout (coarse debris).

Neutrons, especially those arising from a bomb of high rating or an enhanced radiation weapon (ERW), are 10 times more lethal than gamma rays. Shielding against neutrons poses very special problems because the best materials are either very weak structurally, scarce, or very expensive.

I am sure that nobody would wish to purchasè an expensive "nuclear shelter" which would protect his family from the physical effects of a nuclear bomb yet leave him to watch them dying of an overdose of radiations. Much more specific data should be given by suppliers of nuclear shelters. Errors of omission are as important as errors of com- mission. We are after all dealing with a matter of life and death.

Glasgow G2

WiLliam R Greig

\section{Pancreatic transplantation}

SIR,-Your leading article "Pancreatic transplantation" (25 October, p 1091) failed to distinguish between the transplantation of isolated pancreatic islets and islet tissue. Current methods of isolating and purifying rat islets have failed to produce substantial numbers of islets when applied to the human pancreas. Hence Mirkovitch ${ }^{1}$ and later Najarian $^{2}$ abandoned attempts to separate islet and exocrine tissue and instead produced a crude pancreatic digest using collagenasethe "dispersed pancreas." It is this islet tissue which has proved so disappointing in human pancreatic transplantation.

Furthermore, I challenge the statement in the article that "patients treated in this way have not been harmed." Intraportal autotransplantation of this digested pancreas regularly produces an elevation of portal pressure and in one patient produced acute disseminated intravascular coagulation. ${ }^{3}$ Finally, prolongation of rat islet allograft survival by tissue culture prior to transplantation can only be achieved using purified islets. Survival is not prolonged if non-islet pancreatic tissue contaminates the culture and transplantation of these islets. ${ }^{4}$

It is my opinion that safe and effective pancreatic transplantation in the young diabetic patient will only be achieved using purified isolated islets combined with more effective methods of immunosuppression.

R DownING

The Queen Elizabeth Hospital,

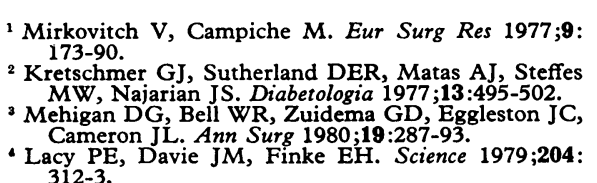

Transplants-are the donors really dead?

SIR,-Having resisted for a month the temptation to re-enter the columns of either the medical or public press, I feel I cannot let pass the allegation by $\mathrm{Mr}$ Deehan (15 November, $p$ 1332) that I have passed off conjecture as fact. He refutes as incorrect my statement that ". . . the previous day I had been offered five minutes to reply to Panorama on a serious programme and the Director-General vetoed it within half an hour." That such a minor scene in this important drama should be replayed so long after it happened suggests that the BBC is anxious to cast doubts on my veracity as a witness, in view of the threatened retrial by television of the technicalities of diagnosing brain death.

My version of the incident is simple and clear. Arrangements had already been made to record my interview, when the producer rang to cancel it. The explanation given to me was that the Director-General had insisted on the inclusion of one of the Panorama team, and that none of them could (? would) participate. Given only that information I consider that my comment was fair. My relations with $\mathrm{Mr}$ Deehan's department have always been 